\title{
Life Smart Fertirrigation: Integrated Pig Manure Processing for Direct Injection of Organic Liquid Fertilizer into Irrigation Systems ${ }^{+}$
}

\author{
Katherine Franco ${ }^{1, *}$, Luis Leyda ${ }^{2}$ and Sven Kallen ${ }^{1}$ \\ 1 Transfer Consultancy, 28001 Madrid, Spain; projects@transferconsultancy.com \\ 2 TEQBIO -Tecnología Ultravioleta, 08034 Barcelona, Spain; leyda@teqbio.com \\ * Correspondence: kathy@transferconsultancy.com \\ + Presented at TERRAenVISION 2019, Barcelona, Spain, 2-7 September 2019. \\ Published: 13 August 2020
}

\begin{abstract}
Spain is Europe's second largest producer of pork with 99.561 pig farms. The excess of manure available in intensive pig breeding areas in combination with lack of land to spread it on, needs addressing. Around 70 million $\mathrm{kg}$ of pig manure is produced daily in the country. A variety of methods exists for slurry processing, although few can be considered as nutrient recovering processes or resource-efficient techniques. Currently, the solid fraction is dried or composted but little attention is paid to the liquid fraction which is considered to be "waste water" and can be expensive to treat. The liquid fraction is either applied directly to crops, left in lagoons to evaporate as much as possible or even illegally dumped into lakes or rivers. These processes cause an enormous environmental impact, increasing greenhouse emissions, polluting water reserves and soil.
\end{abstract}

Keywords: circular economy; green technology; nature-based fertilizer; pig sector

In order to help to solve these problems, LIFE14/ENV/ES/00640 Smart Fertirrigation project foresees to demonstrate the environmental and economic feasibility of innovative pig manure treatment at pig farms in order to produce precise volumes of natural liquid fertilizers for direct injection into irrigation systems. This project addresses three main challenges:

1. Inefficient use of available organic resources in pig manure

2. Negative effects of extensive use of inorganic fertilizers

3. Unbalanced amount of phosphorous $(\mathrm{P})$ in manure used for crop production.

In order to track our environmental problems and demonstrate the implementation of the integrated pig slurry treatment system, we implement different innovative technologies such as the use of fuzzy filter that will drastically decrease the amount of suspended solids in the liquid fraction. Innovative drying equipment considered to be a type of "green machine" will be implemented. The division of work considered three approaches:

1. Apply an innovative treatment in order to recover the liquid fraction with its natural nutrients for direct injection into irrigation systems

2. Use of liquid fertilizer as a substitute for mineral fertilizers, reducing greenhouse gas emission and preventing soil acidification

3. Reduce the amount of $\mathrm{P}$ in the slurry by using new phytase enzymes in pig feed

Expected results:

$50 \%$ cost savings of liquid fertilizers vs inorganic fertilizer

$70 \%$ substitution of inorganic fertilizers in the project area 
Prevention of $\mathrm{CO}_{2}$ emissions vs inorganically fertilized fields

$20 \%$ increase in nutrient absorption capacity of the plant vs inorganic fertilized fields, leading to reduction of nitrogen and phosphorous in the ecosystem

$30 \%$ reduction of phosphorus present in tested pig manure vs manure of conventionally bred

(C) 2020 by the authors. Licensee MDPI, Basel, Switzerland. This article is an open access article distributed under the terms and conditions of the Creative Commons Attribution (CC BY) license (http://creativecommons.org/licenses/by/4.0/). 